\title{
Autonomic dysfunction in children with sleep disordered breathing.
}

Running head: Heart rate variability in children with SDB

Lisa Walter, $\mathrm{PhD}^{1}$, Gillian M Nixon, MD ${ }^{1,2}$, Margot J Davey, $\mathrm{MBBS}^{2}$, Vicki Anderson,

$\mathrm{PhD}^{3,4}$, Adrian M Walker, $\mathrm{PhD}^{1}$, Rosemary SC Horne, $\mathrm{PhD}^{1}$

${ }^{1}$ The Ritchie Centre, Monash Institute of Medical Research, Monash University, Melbourne, Australia

${ }^{2}$ Melbourne Children's Sleep Centre, Monash Children’s Program, Monash Medical Centre, Melbourne, Australia

${ }^{3}$ Critical Care and Neuroscience Research, Murdoch Children's Research Institute, Melbourne, Australia

${ }^{4}$ Psychological Sciences, University of Melbourne, Melbourne, Australia

\section{ADDRESS FOR CORRESPONDENCE AND REPRINT REQUESTS:}

Dr Lisa Walter

The Ritchie Centre

Monash Institute of Medical Research

PO Box 5418

Clayton, Victoria, Australia 3168

Phone: 61395945474

Fax: 61395946811

Email: lisa.walter@monash.edu

KEY WORDS: obstructive sleep apnoea, autonomic nervous system, paediatrics, power spectral analysis 


\begin{abstract}
Purpose

Sleep disordered breathing (SDB) has adverse effects on cardiovascular health in adults, partly due to changes in autonomic activity. However there have been limited studies in children. We analysed the impact of SDB and sleep stage on autonomic control of heart rate in 7-12 y old children, utilizing spectral heart rate variability (HRV) as a measure of autonomic activity.
\end{abstract}

\title{
Methods
}

80 children underwent overnight polysomnography. Subjects were grouped according to their obstructive apnoea-hypopnoea index $(\mathrm{OAHI})$ : controls, $\mathrm{OAHI} \leq 1$ event/h and no history of snoring; primary snorers (PS) OAHI $\leq 1$, mild (OAHI 1-5) and moderate/severe (MS) OAHI >5. HRV was analyzed during Wake, non rapid eye movement (NREM) $1 \& 2$, slow wave sleep (SWS) and REM.

\section{Results}

Compared with controls, Total Power, Low (LF) and High Frequency (HF) power were reduced in all SDB severities during REM. LF/HF ratio was less in MS SDB (median=0.34; range, $0.20-0.49 ; \mathrm{p}<0.05)$ versus controls $(0.38 ; 0.26-0.55 ; \mathrm{p}<0.05)$ and PS $(0.39 ; 0.23$ 0.57; $<0.05$ ) during SWS. In all groups, Total Power, LF and HF power were highest during NREM1\&2 while LF/HF ratio was lowest during SWS. Blood pressure was elevated in SDB in all sleep states.

\section{Conclusions}

HRV was altered in 7-12 y old children with SDB, which may signify an overall depression of autonomic tone, perhaps a consequence of their elevated blood pressure during sleep coupled with repeated exposure to SDB event-related cardiovascular disturbance. Further 
research is warranted to elucidate the long-term effects on the cardiovascular system of subjects exhibiting impaired HRV and elevated BP in childhood. 


\section{Introduction}

Snoring occurs in up to $35 \%$ of children [1] and is the hallmark symptom of sleep disordered breathing (SDB). SDB ranges in severity from primary snoring through to obstructive sleep apnoea. In children, SDB has detrimental effects on cardiovascular health, evidenced by the development of high blood pressure (BP), increased blood pressure variability (BPV), decreased nocturnal blood pressure (BP) dipping, increased C-reactive protein indicative of a a pro-inflammatory state, a higher left ventricular (LV) mass and early LV diastolic dysfunction [2-6]. Studies in adults suggest that these adverse effects on the cardiovascular system are due to changes in autonomic activity, as indicated by changes in BPV and heart rate variability (HRV) [7-9]. In adults an association between hypoxemia and elevated sympathetic nervous tone has been demonstrated, which is believed to be linked to the pathogenic effects of SDB on cardiovascular health [10-13]. However, there have been limited studies investigating autonomic activity in children with SDB and these have reported conflicting findings.

Power spectral analysis of HRV is a well recognized method of assessing overall changes in cardiovascular nervous control. The output of HRV spectral analysis is typically divided into low frequency (LF) considered to be mediated by both the parasympathetic and sympathetic nervous systems and high frequency (HF) spectra represents only parasympathetic activity [14-18].

In both adults and children with SDB, typically at apnoea onset there is a progressive bradycardia followed by an abrupt tachycardia at event termination, which transiently increase variability in both heart rate (HR) and BP [19, 20]. Known determinants of HRV that have received scant attention in children suffering SDB are sleep stage and age, both of which significantly influence HRV in normal populations of children [21]. Using spectral analyses, we aimed to determine whether HRV was altered in children with SDB compared 
to non-snoring controls and whether any observed changes in HRV were associated with SDB severity or with sleep stage. We hypothesized that, similar to adults, sympathovagal balance would be altered in children with SDB compared with normal non-snoring controls and that this would be most marked in REM sleep.

\section{Methods}

Ethics approval for this study was granted by the Southern Health (05052C) and Monash University (2005/459) Human Research Ethics Committees. Written informed consent was obtained from parents, and verbal assent from children prior to commencement of the study. No monetary incentive was provided for participation.

\section{Subjects}

Participants for this study were randomly selected retrospectively from 141 7-12 year old children participating in a larger study of the cardiovascular and neurocognitive effects of SDB, data from which has been published previously [5, 22-24]. We recruited 7-12 year old children referred for assessment of SDB between April 2004 and February 2008, along with an age-matched control group with no history or parental concerns of snoring from the community. All children underwent a complete medical examination prior to an overnight polysomnography (PSG) study and were well on the night of the study. Children with conditions known to affect sleep, breathing, or blood pressure, such as such as craniofacial syndromes, genetic syndromes, mental retardation, cerebral palsy, previous otolaryngologic surgery, cardiac or renal disease, and children taking medications affecting airway patency, such as nasal steroids were excluded. Children with asthma who were not using long-acting beta agonists were included, but Salbutamol was not taken within 24 hours of the sleep study. For this analysis of HRV, we decided to only analyse a sub-sample of the entire cohort. This was because the largest individual severity group was overwhelmingly the primary snoring group who do not have many obstructive respiratory events, which may have skewed the 
data. Additionally, HRV is a very time consuming procedure and most studies that report on HRV have cohorts much smaller than the 80 children analysed in our study. Therefore, we decided to analyse an even number of 20 children per group. The 20 children from each group were randomly chosen.

Children were grouped according to their obstructive apnoea hypopnoea index (OAHI), defined as the total number of obstructive apnoeas, mixed apnoeas, and obstructive hypopnoeas per hour of total sleep time. Children were classified as having primary snoring (PS, OAHI $\leq 1$ event/h); mild OSA (OAHI between $>1-5$ events/h); or moderate/severe OSA (MS, OAHI $>5$ events/h). Control children had an OAHI $\leq 1$ event $/ \mathrm{h}$ and no evidence of snoring.

\section{Recording methods}

PSG was performed using a commercially available PSG system (Series S or E Sleep System, Compumedics, Melbourne, Australia) as previously published [18] Electroencephalograms (EEG; C4-A1, O2-A1), left and right electrooculograms (EOG), submental electromyogram (EMG), left and right anterior tibialis muscle EMG and electrocardiogram (ECG) were recorded. The ECG had a sampling rate of $512 \mathrm{~Hz}$. Oxygen saturation $\left(\mathrm{SaO}_{2}\right)$, thoracic and abdominal breathing movements, both end tidal and transcutaneous $\mathrm{CO}_{2}$, and airflow via nasal pressure and oronasal thermistor were also recorded. Following the study, data were transferred via European data format to data analysis software (LabChart 6, ADInstruments, Sydney, Australia) for analysis.

\section{Sleep Data Analysis}

Sleep and arousals were scored according to standard criteria in 30s epochs [25, 26]. Respiratory events were $\geq 2$ respiratory cycles in duration. Obstructive apnoeas, mixed 
apnoeas and hypopnoeas were scored using standard criteria (hypopnoea desaturation criterion $\geq 3 \%$ ) [27]. Sleep stages NREM 1 and 2 were combined (NREM1\&2) as were NREM 3 and 4 (SWS). The total arousal index (Total AI) was defined as the total number of cortical and subcortical spontaneous, respiratory and periodic leg movement arousals per hour of TST.

\section{BP Analysis}

In addition to the standard paediatric PSG, continuous BP recordings were made using finger photoplethysmography (FinometerTM, Finapres Medical Systems, Arnhem, The Netherlands) [28]. The sensor is placed on the middle phalanx of the middle finger of the dominant hand. Beat to beat BP data were then grouped according to sleep stage (Wake, NREM1\&2, SWS, REM) and a mean value for each subject calculated.

\section{Heart rate variability analysis}

Every 2 min epoch from the entire overnight study (including respiratory events) that was free of movement artifact (disruption to the ECG signal caused by gross body movement) on the ECG signal was selected. 2 min epochs were chosen to maximise the overall number of artifact-free epochs available for analysis while ensuring an adequate length of time to accommodate enough oscillations within the LF range to detect changes. Periods of wakefulness during the sleep period were excluded. Each 2 min epoch was separated from the previous epoch by at least 30s. The intervening 30s epochs were EEG artifact free and did not include a sleep stage change. The 2 min epochs were then grouped according to sleep stage (Wake, NREM1\&2, SWS, REM) and a mean value for each subject calculated.

\section{Power spectral analysis of $\mathrm{HRV}$}


For each 2 min epoch, the power spectral density for the LF (0.04-0.15 Hz) and HF (0.15-0.4 $\mathrm{Hz}$ ) bands [29]. Total power represents the total power in the spectrum for the analysis region $(\leq 0.4 \mathrm{~Hz})$. The $\mathrm{LF} / \mathrm{HF}$ ratio was determined as a measure of sympathovagal balance. Normalized values of LF and HF were not used, as they are mathematically equivalent to the $\mathrm{LF} / \mathrm{HF}$ ratio and do not add information beyond that measure. In order to address the issue of stationarity during respiratory events and arousals, the data were re-analyzed during stable sleep following the removal of all epochs containing respiratory events and arousals. Additionally, the first 6 minutes following a change in sleep stage was analyzed to determine if there was an initial change in HRV that could be attributed to the impetus of the change of stage rather than to the stage as a whole.

\section{Statistical Analysis}

Statistical analyses were performed using SPSS® (IBM® Statistics version 19). Data were first tested for normality and equal variance. Demographic data and polysomnographic characteristics were compared between diagnostic groups using Kruskal-Wallis 1-way ANOVA on Ranks with Mann Whitney U-test post hoc analyses. HRV data were log transformed and analysed using univariate analyses with Bonferroni corrections with HR included as a covariate, to determine sleep stage and diagnostic group differences. Stepwise multiple linear regressions were performed to determine significant predictors of HRV, with HRV parameters entered as the dependant variable and SDB severity, BP, age, gender and BMI z-score entered as the independent variables. Data are presented as either mean \pm SEM or median and inter quartile range. $\mathrm{P}<0.05$ was considered significant.

\section{Results}


Demographic and polysomnographic data are presented in Table 1. The groups did not differ in age. BMI z-score was significantly higher in the MS group compared to Controls. Both the Control and PS groups had significantly longer TST than the MS group. Children with PS spent more time in NREM1\&2 and less time in SWS than did the Mild OSA group.

\section{Overnight BP and HR}

Mean arterial pressure (MAP) and HR for Wake and each sleep stage are presented in Table

2. Significant between group differences are in comparison to the control group; during Wake and NREM $1 \& 2$ children with all severities of SDB, and during SWS and REM the Mild and MS groups had higher MAP. In all sleep stages, the MS group had significantly higher HR compared with the control group.

\section{Power spectral analysis of HRV}

\section{Between diagnostic group comparisons.}

Data for LF, HF and Total power are presented in Table 3. There were no significant differences between diagnostic groups during Wake, NREM1\&2 or SWS for LF, HF or Total power, or during REM for HF power. An overall significant difference was identified in LF and Total power between diagnostic groups during REM sleep, but where the differences lay could not be determined. There were no significant differences between diagnostic groups during Wake, NREM1\&2 or REM for the LF/HF ratio. During SWS the LF/HF ratio was significantly lower in the MS OSA group compared with the control and PS groups.

\section{Between sleep stage comparisons.}

Data for between sleep stage comparisons for LF, HF, total power and the LF/HF ratio are presented in Figure 1 A-D respectively. LF power was significantly lower during SWS compared to Wake and the other sleep stages in all severities of SDB, except in the MS group where SWS was not different to REM (Fig. 1a). LF power was significantly higher during 
NREM1\&2 compared with REM in the PS and Mild OSA groups, and compared with Wake in the Mild OSA group.

HF power (Fig. 1b) during NREM1\&2 was significantly higher in all diagnostic groups compared with Wake, in the control, PS and Mild OSA groups compared with REM, and in the PS and Mild groups compared with SWS.

Total power (Fig. 1c) was lower during SWS compared with NREM1\&2 for all diagnostic groups. In the PS and Mild groups Total power was higher during NREM1\&2 when compared with REM and in the Mild OSA group when compared with Wake.

In all diagnostic groups, the LF/HF ratio (Fig. 1d) was significantly higher during Wake when compared to NREM1\&2 and SWS, and compared to REM in the Mild OSA group. The $\mathrm{LF} / \mathrm{HF}$ ratio was significantly lower during SWS compared the other sleep stages in all diagnostic groups. LF/HF was only lower during NREM1\&2 compared with REM in the control group.

Data for the HRV variables during stable sleep when all respiratory events and arousals were excluded are presented in Table 4. While absolute values of spectral power are lower compared to those where respiratory events and arousals were included, identical patterns of spectral power across all frequencies to that observed during total sleep were observed.

Similarly, analysis of only the first 6 minutes following a change of sleep stage also had the same pattern of spectral power as the entire stage (data not shown).

\section{Determinants of HRV}

Significant predictors of HRV are presented in Table 5. Age, gender, BMI Z-score or BP did not make a significant contribution to HRV during sleep. Age was a significant, common predictor of LF and total power during Wake. BMI Z-score was a predictor of HF power during Wake and SDB severity was a predictor of LF power during SWS and REM.

\section{Discussion}


The current study comprehensively investigates autonomic heart rate control as assessed by HRV, both across a broad range of SDB severities and across sleep stages. We have identified a significant reduction in HRV during sleep in 7-12 y old children with SDB compared to non-snoring control children, and confirmed that these differences remain after exclusion of SDB events from the analysis. Our findings suggest that SDB of any severity has significant effects on the cardiovascular system in these young children. We also found that sleep stage had a marked effect on HRV. During REM sleep, children with SDB had reduced autonomic activity overall, with lower total, HF and LF power compared with controls, whereas during SWS, the children with Mild and MS OSA had reduced sympathovagal balance. We suggest that the increased BP that occurs during sleep in children with SDB observed in other studies[3,5] and confirmed in the current study, is associated with reduced autonomic tone, most prominently during REM sleep; notably, this reduction persists even when respiratory events and arousals are removed.

We had hypothesized that children with SDB would have altered sympathovagal balance during REM sleep, whereas we observed a reduction of sympathovagal balance during SWS and reduced power across all frequencies during REM sleep. Our results are similar to other studies in adults [8] and previous studies which examined more limited severities of SDB in children [30-36]. These reported that cardiac autonomic activity was reduced in subjects with SDB, with the extent related to the severity of the SDB. However, compared to the current study, different methodologies were used to categorize control and SDB subjects, and to acquire, analyze and interpret data. Aljadeff et al, used Poincaré plots and demonstrated that children with OSA had enhanced beat-to-beat HRV in children at slow HRs and reduced HRV at high HRs. However, as there were only 7 OSA children and 7 children with PS as a control group in the study [30], the conclusions require verification. Power spectral analysis in a similarly small cohort of 10 children with OSA and 10 normal control children in 
contrast to our study, showed increased sympathetic activity in the OSA group during REM sleep and parasympathetic predominance during SWS in the controls [31]. Similar to the current study, O'Brien et al, [32] and Chaicharn et al, [34] also demonstrated autonomic dysfunction in children with SDB, both studies comparing single groups of children with OSA to control groups. However, O'Brien's results differed from ours in that they demonstrated that peripheral vascular reactivity induced by sympathetic activity increased in children with SDB during sigh manoeuvres and a cold pressor test during wakefulness, whereas we did not have a direct measure of sympathetic activity and our results indicate reduced autonomic tone overall in children with SDB. Chaicharn used mathematical modelling to relate changes in HRV to respiration and BPV, and also reported cardiovascular sympathetic activity is elevated in children with OSA. In addition, a recent study by Montesano et al, [33] reported increased basal sympathetic activity during wakefulness and reduced HRV during deep breathing in OSAS patients compared with controls. Comparing pre- and post-adenotonsillectomy in 18 children Muzumdar et al, [36] found that LF and HF increased during sleep following adenotonsillectomy, which concurs with our data comparing children with OSA to non-snoring controls.

Our data suggest that the dramatic changes in the cardiovascular system observed during and immediately following apnoeas result in persisting HRV changes that last beyond the apnoeic episodes and impact on the HRV of the entire sleep stage. Thus SDB affects the normal autonomic control of HR that characterises sleep in normal, healthy children. This was confirmed by further analysis of HRV during stable sleep when epochs containing respiratory events, arousals and movements were removed prior to analysis. Although the absolute values of the HRV measures were consistently lower during stable sleep in both controls and children with SDB, as would be anticipated, they displayed identical patterns to the whole overnight recording that included such events. Deng et al, [35] systematically compared 
various time-series metrics for the quantification of HRV in children with OSA from ECG recordings alone and reported $\mathrm{HRV}$ can be used as a reliable diagnostic tool for OSA, especially if spectral analysis is used in conjunction with non-linear techniques such as numerical titration. However, our extended analysis of HRV during stable sleep verified in this study that any effect upon stationarity of HR due to bradycardia and tachycardia associated with apnoeic events did not influence the pattern of HRV either between sleep stages or between severity groups. Similarly, the analyses during the first six minutes following a change in sleep stage showed the same pattern of HRV indices as the overnight analyses, indicating that the physiological effect of the change in sleep stage on HRV remained constant throughout the stage, and was not a reflection of the dynamics of the change itself.

SDB had no major affect on the normal patterns of sleep state-related HRV observed in the non- snoring control children. In both SDB and control children, total, LF and HF power increased from Wake to NREM1\&2, decreased during SWS and increased again during REM. In contrast, the LF/HF ratio decreased progressively from Wake, through NREM1\&2 to SWS and then increased during REM. A previous study in normal healthy children concluded that autonomic balance was shifted towards parasympathetic dominance during normal SWS [21]. Similarly, the shift in HF in our study indicates an increase in parasympathetic activity from Wake to NREM1\&2 sleep and a commensurate shift in sympathovagal balance (LF/HF) during NREM1\&2 and SWS in both control and children with all severities of SDB, though interpreting changes in LF power are more problematic. As the vagal components of the LF and HF power spectra have a non-linear relationship, it is erroneous to assume that a change in LF activity accompanied by a corresponding change in $\mathrm{LF} / \mathrm{HF}$ ratio necessarily indicates a change in sympathetic activity. 
Stepwise multiple linear regression analysis performed to identify potential physiological determinants of HRV, indicated that SDB severity was a significant negative predictor of LF power during both SWS and REM sleep. This is in accordance with the reduced LF power we found during REM and SWS in children with SDB compared with controls; although we could not statistically identify the group differences during SWS, there was a trend for decreased LF power during SWS. Analysis failed to show that either age, gender, BMI Zscore nor BP had any significant effects on HRV during sleep. Our finding that BMI was not associated with changes in HRV during sleep, appears to be contrary to previous literature that has shown childhood obesity is associated with an increased risk of cardiovascular disease in later life [37], however, the children in the current study were not morbidly obese which may have dampened the effect of obesity on HRV.

In conclusion, our data demonstrate significant changes to the HRV of 7-12 y old children with SDB. We postulate that the acute changes in BP and the tachycardia and bradycardia that are associated with obstructive respiratory events, coupled with the chronic, elevated BP during sleep in children with SDB, adversely impact on the autonomic control of heart rate during sleep as reflected in reduced HRV in these children. Further research is required to elucidate the long-term effects on the cardiovascular system of children with impaired HRV and hypertension as they age to adulthood.

\section{Acknowledgements}

The authors would like to thank the staff of the Melbourne Children's Sleep Centre for their help and advice and the parents and children who participated in this study.

\section{Funding}


Funding for this project was awarded by the National Health and Medical Research Council of Australia [Project Grant Number 384142] and supported by the Victorian Government's Operational Infrastructure Support Program.

\section{Conflict of interests}

None of the authors of this manuscript declare any conflict of interest. 


\section{References}

[1] Castronovo V, Zucconi M, Nosetti L, Marazzini C, Hensley M, Veglia F, Nespoli L, Ferini-Strambi L (2003) Prevalence of habitual snoring and sleep-disordered breathing in preschool-aged children in an Italian community. J Pediatr; 142:377-382.

[2] Amin R, Somers VK, McConnell K, Willging P, Myer C, Sherman M, McPhail G, Morgenthal A, Fenchel M, Bean J, Kimball T, Daniels S (2008) Activity-adjusted 24hour ambulatory blood pressure and cardiac remodeling in children with sleep disordered breathing. Hypertension; 51:84-91.

[3] Bixler EO, Vgontzas AN, Lin HM, Liao D, Calhoun S, Fedok F, Vlasic V, Graff G (2008) Blood pressure associated with sleep-disordered breathing in a population sample of children. Hypertension; 52:841-846.

[4] Li AM, Au CT, Sung RY, Ho C, Ng PC, Fok TF, Wing YK (2008) Ambulatory blood pressure in children with obstructive sleep apnoea: A community based study. Thorax; 63:803-809.

[5] Horne RS, Yang JS, Walter LM, Richardson HL, O'Driscoll DM, Foster AM, Wong S, Ng ML, Bashir F, Patterson R, Nixon GM, Jolley D, Walker AM, Anderson V, Trinder J, Davey MJ (2011) Elevated blood pressure during sleep and wake in children with sleep-disordered breathing. Pediatrics; 128:e85-92.

[6] Villa MP, Ianniello F, Tocci G, Evangelisti M, Miano S, Ferrucci A, Ciavarella GM, Volpe M (2012) Early cardiac abnormalities and increased c-reactive protein levels in a cohort of children with sleep disordered breathing. Sleep Breath; 16:101-110.

[7] Parish JM, Somers VK (2004) Obstructive sleep apnea and cardiovascular disease. Mayo Clin Proc; 79:1036-1046. 
[8] Aydin M, Altin R, Ozeren A, Kart L, Bilge M, Unalacak M (2004) Cardiac autonomic activity in obstructive sleep apnea: Time-dependent and spectral analysis of heart rate variability using 24-hour holter electrocardiograms. Tex Heart Inst J; 31:132-136.

[9] da Silva SP, Hulce VD, Backs RW (2009) Effects of obstructive sleep apnea on autonomic cardiac control during sleep. Sleep Breath; 13:147-156.

[10] Imadojemu VA, Gleeson K, Gray KS, Sinoway LI, Leuenberger UA (2002) Obstructive apnea during sleep is associated with peripheral vasoconstriction. Am J Respir Crit Care Med; 165:61-66.

[11] Leuenberger U, Jacob E, Sweer L, Waravdekar N, Zwillich C, Sinoway L (1995) Surges of muscle sympathetic nerve activity during obstructive apnea are linked to hypoxemia. J Appl Physiol; 79:581-588.

[12] Smith ML, Niedermaier ON, Hardy SM, Decker MJ, Strohl KP (1996) Role of hypoxemia in sleep apnea-induced sympathoexcitation. J Auton Nerv Syst; 56:184190.

[13] Somers VK, Dyken ME, Clary MP, Abboud FM (1995) Sympathetic neural mechanisms in obstructive sleep apnea. J Clin Invest; 96:1897-1904.

[14] Akselrod S, Gordon D, Madwed JB, Snidman NC, Shannon DC, Cohen RJ (1985) Hemodynamic regulation: Investigation by spectral analysis. Am J Physiol; 249:H867-875.

[15] Akselrod S, Gordon D, Ubel FA, Shannon DC, Berger AC, Cohen RJ (1981) Power spectrum analysis of heart rate fluctuation: A quantitative probe of beat-to-beat cardiovascular control. Science; 213:220-222.

[16] Pagani M, Lombardi F, Guzzetti S, Rimoldi O, Furlan R, Pizzinelli P, Sandrone G, Malfatto G, Dell'Orto S, Piccaluga E (1986) Power spectral analysis of heart rate and 
arterial pressure variabilities as a marker of sympatho-vagal interaction in man and conscious dog. Circ Res; 59:178-193.

[17] Pomeranz B, Macaulay RJ, Caudill MA, Kutz I, Adam D, Gordon D, Kilborn KM, Barger AC, Shannon DC, Cohen RJ, Benson H (1985) Assessment of autonomic function in humans by heart rate spectral analysis. Am J Physiol; 248:H151-153.

[18] Trinder J, Padula M, Berlowitz D, Kleiman J, Breen S, Rochford P, Worsnop C, Thompson B, Pierce R (2001) Cardiac and respiratory activity at arousal from sleep under controlled ventilation conditions. J Appl Physiol; 90:1455-1463.

[19] Penzel T, Kantelhardt JW, Lo CC, Voigt K, Vogelmeier C (2003) Dynamics of heart rate and sleep stages in normals and patients with sleep apnea. Neuropsychopharmacology; 28:S48-S53.

[20] O'Driscoll D, Foster AM, Ng ML, Yang JSC, Bashir F, Nixon GM, Davey MJ, Anderson V, Walker AM, Trinder J, Horne RSC (2009) Acute cardiovascular changes with obstructive events in children with sleep disordered breathing. Sleep; 32:12651271.

[21] Baharav A, Kotagal S, Gibbons V, Rubin BK, Pratt G, Reegt KJ, Akselrod S (1995) Fluctuations in autonomic nervous activity during sleep displayed by power spectrum analysis of heart rate variability. Neurology; 45:1183-1187.

[22] Bourke R, Anderson V, Yang JS, Jackman AR, Killedar A, Nixon GM, Davey MJ, Walker AM, Trinder J, Horne RS (2011) Cognitive and academic functions are impaired in children with all severities of sleep-disordered breathing. Sleep Med; $12: 489-496$.

[23] Yang JS, Nicholas CL, Nixon GM, Davey MJ, Anderson V, Walker AM, Trinder JA, Horne RS (2010) Determining sleep quality in children with sleep disordered 
breathing: EEG spectral analysis compared with conventional polysomnography. Sleep; 33:1165-1172.

[24] Bourke RS, Anderson V, Yang JS, Jackman AR, Killedar A, Nixon GM, Davey MJ, Walker AM, Trinder J, Horne RS (2011) Neurobehavioral function is impaired in children with all severities of sleep disordered breathing. Sleep Med; 12:222-229.

[25] ADSA (1992) EEG arousals scoring rules and examples: A preliminary report from the Sleep Disorders Atlas Task Force of the American Sleep Disorders Association. Sleep; 15:173-184.

[26] Rechtschaffen A, Kales A (1968) A manual of standardized terminology, techniques and scoring systems for sleep stages of human subjects. Washington DC, USA: U.S. Government Printing Office.

[27] Americam Thoracic Society (1996) Standards and indications for cardiopulmonary sleep studies in children. Am J Crit Care Med; 153:866-878.

[28] Maestri R, Pinna GD, Robbi E, Capomolla S, La Rovere MT (2005) Noninvasive measurement of blood pressure variability: Accuracy of the finometer monitor and comparison with the finapres device. Physiol Meas; 26:1125-1136.

[29] Task Force of the European Society of Cardiology and the North American Society of Pacing and Electrophysiology (1996) Heart rate variability, standards of measurement, physiological interpretation, and clinical use. European Heart Journal; $17: 354-381$.

[30] Aljadeff G, Gozal D, Schechtman VL, Burrell B, Harper RM, Ward SL (1997) Heart rate variability in children with obstructive sleep apnea. Sleep; 20:151-157.

[31] Baharav A, Kotagal S, Rubin BK, Pratt J, Akselrod S (1999) Autonomic cardiovascular control in children with obstructive sleep apnea. Clin Auton Res; 9:345-351. 
[32] O'Brien LM, Gozal D (2005) Autonomic dysfunction in children with sleepdisordered breathing. Sleep; 28:747-752.

[33] Montesano M, Miano S, Paolino MC, Massolo AC, Ianniello F, Forlani M, Villa MP (2010) Autonomic cardiovascular tests in children with obstructive sleep apnea syndrome. Sleep; 33:1349-1355.

[34] Chaicharn J, Lin Z, Chen ML, Ward SL, Keens T, Khoo MC (2009) Model-based assessment of cardiovascular autonomic control in children with obstructive sleep apnea. Sleep; 32:927-938.

[35] Deng ZD, Poon CS, Arzeno NM, Katz ES (2006) Heart rate variability in pediatric obstructive sleep apnea. in Proceedings of the 28th IEEE EMBS Annual International Conference. New York City, USA.

[36] Muzumdar HV, Sin S, Nikova M, Gates G, Kim D, Arens R (2011) Changes in heart rate variability after adenotonsillectomy in children with obstructive sleep apnea. Chest; 139:1050-1059.

[37] Mahoney LT, Burns TL, Stanford W, Thompson BH, Witt JD, Rost CA, Lauer RM (1996) Coronary risk factors measured in childhood and young adult life are associated with coronary artery calcification in young adults: The muscatine study. $\mathbf{J}$ Am Coll Cardiol; 27:277-284. 
Figure Legend

Fig. 1 Sleep stage comparison of the power spectral analysis of (a) low frequency (LF), (b) high frequency $(\mathrm{HF}),(\mathrm{c})$ total power and (d) LF/HF ratio within each diagnostic group in 712 y old children with sleep disordered breathing and non-snoring controls. Columns that do not share a letter in common are statistically different. $p<0.05$ considered statistically different 
Table 1 Subject Demographic and Polysomnographic Characteristics

\begin{tabular}{|c|c|c|c|c|c|}
\hline & Control & PS & $\mathrm{M}$ & MS & $\mathrm{P}$ \\
\hline $\mathrm{N}$ (males) & $20(12)$ & $20(18)$ & $20(11)$ & $20(8)$ & \\
\hline Age $(y)$ & $\begin{array}{c}9.2 \\
(72-120)\end{array}$ & $\begin{array}{l}10.0 \\
3-123\end{array}$ & $\begin{array}{l}8.2 \\
(71-115)\end{array}$ & $\begin{array}{c}9.0 \\
(72-126)\end{array}$ & 0.17 \\
\hline BMI z-score & $\begin{array}{c}0.50 * \\
(-0.86-2.31)\end{array}$ & $\begin{array}{c}0.90 \\
(-2.2-3.0)\end{array}$ & $\begin{array}{c}0.55 \\
(-0.8-2.70)\end{array}$ & $\begin{array}{c}1.6 \\
(-1.1-2.50)\end{array}$ & 0.02 \\
\hline TST (h) & $\begin{array}{c}413.3^{*} \\
(293.0-494.5)\end{array}$ & $\begin{array}{c}424.8^{*} \\
(334.5-483.5)\end{array}$ & $\begin{array}{c}393.0 \\
(300.0-468.5)\end{array}$ & $\begin{array}{c}363.5 \\
(238.0-448.5)\end{array}$ & 0.006 \\
\hline Sleep Efficiency & $\begin{array}{c}87.9 \% * \\
(64.8-97.1)\end{array}$ & $\begin{array}{c}84.7 \% \\
(69.0-97.3)\end{array}$ & $\begin{array}{c}81.0 \% \\
(60.6-92.8)\end{array}$ & $\begin{array}{c}77.4 \% \\
(59.4-95.2)\end{array}$ & 0.02 \\
\hline NREM1\&2 (\%TST) & $\begin{array}{c}56.1 \\
(47.0-66.3)\end{array}$ & $\begin{array}{c}60.8 \dagger \\
(54.4-69.0)\end{array}$ & $\begin{array}{c}55.0 \\
(45.8-63.8)\end{array}$ & $\begin{array}{c}58.7 \\
(50.1-74.4)\end{array}$ & 0.02 \\
\hline SWS (\%TST) & $\begin{array}{c}24.4 \\
(16.4-36.1)\end{array}$ & $\begin{array}{c}22.7 \dagger \\
(18.0-30.5)\end{array}$ & $\begin{array}{c}29.3 \\
(16.7-38.2)\end{array}$ & $\begin{array}{c}24.1 \\
(14.0-36.1)\end{array}$ & 0.02 \\
\hline REM (\%TST) & $\begin{array}{c}17.6 \\
(12.0-23.2)\end{array}$ & $\begin{array}{c}16.6 \\
(11.4-23.6)\end{array}$ & $\begin{array}{c}17.3 \\
(9.7-26.1)\end{array}$ & $\begin{array}{c}14.9 \\
(1.5-28.7)\end{array}$ & 0.59 \\
\hline OAHI (events/h) & $\begin{array}{c}0.0 \\
(0.0-0.5)\end{array}$ & $\begin{array}{c}0.3 \\
(0.0-0.9)\end{array}$ & $\begin{array}{c}2.5 \\
(1.1-4.5)\end{array}$ & $\begin{array}{c}12.9 \\
(5.6-48.9)\end{array}$ & - \\
\hline Total AI (events/h) & $\begin{array}{c}11.3 * \\
(7.0-18.1)\end{array}$ & $\begin{array}{c}11.1^{*} \\
(7.6-28.4)\end{array}$ & $\begin{array}{c}14.1 * \\
(9.3-27.4)\end{array}$ & $\begin{array}{c}22.6 \\
(9.8-57.5)\end{array}$ & - \\
\hline $\mathrm{SpO}_{2}$ nadir $(\%)$ & $\begin{array}{c}95.0 * \\
(78.0-98.0)\end{array}$ & $\begin{array}{c}93.5^{*} \\
(87.0-98.0)\end{array}$ & $\begin{array}{c}92.5^{*} \\
(88.0-97.0)\end{array}$ & $\begin{array}{c}87.5 \\
(73.0-94.0)\end{array}$ & $<0.0001$ \\
\hline
\end{tabular}

Data are expressed as median (range). PS: Primary Snoring; M: Mild OSA; MS: Moderate-Severe OSA; BMI , body mass index; TST, total sleep time; NREM, non rapid eye movement; SWS, slow wave sleep; REM, rapid eye movement; OAHI, obstructive apnoea hypopnoea index; Total AI, total arousal index; $\mathrm{SpO}_{2}$, oxygen saturation. $\mathrm{P}<0.05$ is considered significant. * vs $\mathrm{MS} \uparrow$ vs $\mathrm{M}$ 
Table 2 Average mean arterial pressure (MAP) and HR in children with either primary snoring, mild or moderate/severe OSA and non-snoring control children, during quiet wakefulness before lights out and during each sleep stage

\begin{tabular}{lcccc}
\hline & Control & PS & Mild & MS \\
\hline MAP (mmHg) & & & & \\
Wake & $62 \pm 2$ & $71 \pm 3^{*}$ & $69 \pm 2^{*}$ & $75 \pm 3^{*}$ \\
NREM1\&2 & $62 \pm 2$ & $67 \pm 2^{*}$ & $69 \pm 2^{*}$ & $74 \pm 2^{*}$ \\
SWS & $60 \pm 1$ & $63 \pm 2$ & $69 \pm 3^{*}$ & $69 \pm 3^{*}$ \\
REM & $68 \pm 2$ & $72 \pm 2$ & $78 \pm 3^{*}$ & $80 \pm 3^{*}$ \\
HR & & & & \\
Wake & $83 \pm 2$ & $85 \pm 2$ & $85 \pm 2$ & $92 \pm 2^{*}$ \\
NREM1\&2 & $70 \pm 1$ & $74 \pm 2$ & $74 \pm 2$ & $80 \pm 2^{*}$ \\
SWS & $74 \pm 1$ & $75 \pm 2$ & $75 \pm 2$ & $83 \pm 2^{*}$ \\
REM & $74 \pm 1$ & $76 \pm 1$ & $78 \pm 2$ & $84 \pm 2^{*}$ \\
\hline
\end{tabular}

PS, primary snorers; MS, moderate/severe obstructive sleep apnoea.

Data presented as mean \pm sem $* \mathrm{p}<0.05$ vs Control; $+\mathrm{p}<0.05$ REM vs Wake 
Table 3 Power spectral analysis of HRV comparing diagnostic groups within each sleep stage

\begin{tabular}{|c|c|c|c|c|c|}
\hline & Control & PS & $\mathrm{M}$ & $\mathrm{M} / \mathrm{S}$ & $\mathrm{P}$ \\
\hline \multicolumn{6}{|c|}{$\mathrm{LF}\left(\mathrm{ms}^{2}\right)$} \\
\hline Wake & $\begin{array}{c}1413 \\
(957-3589)\end{array}$ & $\begin{array}{c}1408 \\
(854-2007)\end{array}$ & $\begin{array}{c}954 \\
(538-2260)\end{array}$ & $\begin{array}{c}1305 \\
(708-2400)\end{array}$ & ns \\
\hline NREM1\&2 & $\begin{array}{c}2053 \\
(738-3632)\end{array}$ & $\begin{array}{c}2147 \\
(1035-3557)\end{array}$ & $\begin{array}{c}1637 \\
(1086-3296)\end{array}$ & $\begin{array}{c}1816 \\
(922-2653)\end{array}$ & ns \\
\hline SWS & $\begin{array}{c}1073 \\
(418-2217)\end{array}$ & $\begin{array}{c}813 \\
(258-1798)\end{array}$ & $\begin{array}{c}429 \\
(264-1350)\end{array}$ & $\begin{array}{c}464 \\
(263-1209)\end{array}$ & $\mathrm{ns}$ \\
\hline REM & $\begin{array}{c}2056 \\
(555-3966)\end{array}$ & $\begin{array}{c}1449 \\
(719-2108)\end{array}$ & $\begin{array}{c}1071 \\
(648-2061)\end{array}$ & $\begin{array}{c}1428 \\
(751-2499)\end{array}$ & 0.046 \\
\hline \multicolumn{6}{|c|}{$\mathrm{HF}\left(\mathrm{ms}^{2}\right)$} \\
\hline Wake & $\begin{array}{c}2398 \\
(863-4227)\end{array}$ & $\begin{array}{c}913 \\
(785-3916)\end{array}$ & $\begin{array}{c}697 \\
(361-3559)\end{array}$ & $\begin{array}{c}1257 \\
(459-1953)\end{array}$ & ns \\
\hline NREM1\&2 & $\begin{array}{c}4746 \\
(1643-6112)\end{array}$ & $\begin{array}{c}2285 \\
(1625-5425)\end{array}$ & $\begin{array}{c}2616 \\
(1334-5607)\end{array}$ & $\begin{array}{c}2031 \\
(1464-4314)\end{array}$ & $\mathrm{ns}$ \\
\hline SWS & $\begin{array}{c}3809 \\
(1003-5739)\end{array}$ & $\begin{array}{c}1519 \\
(868-5086)\end{array}$ & $\begin{array}{c}1378 \\
(533-2765)\end{array}$ & $\begin{array}{c}1717 \\
(812-3889)\end{array}$ & ns \\
\hline REM & $\begin{array}{c}3556 \\
(992-6236)\end{array}$ & $\begin{array}{c}1513 \\
(723-2940)\end{array}$ & $\begin{array}{c}1421 \\
(601-2668)\end{array}$ & $\begin{array}{c}1543 \\
(611-4425)\end{array}$ & 0.048 \\
\hline \multicolumn{6}{|c|}{ Total Power $\left(\mathrm{ms}^{2}\right)$} \\
\hline Wake & $\begin{array}{c}6278 \\
(4248-12119)\end{array}$ & $\begin{array}{c}4307 \\
(2931-11574)\end{array}$ & $\begin{array}{c}2864 \\
(1901-10878)\end{array}$ & $\begin{array}{c}4287 \\
(2915-8325)\end{array}$ & ns \\
\hline NREM1\&2 & $\begin{array}{c}8343 \\
(3426-13515)\end{array}$ & $\begin{array}{c}6700 \\
(4190-13595)\end{array}$ & $\begin{array}{c}6407 \\
(3997-13053)\end{array}$ & $\begin{array}{c}5708 \\
(3775-10564)\end{array}$ & ns \\
\hline SWS & $\begin{array}{c}6459 \\
(1763-10111)\end{array}$ & $\begin{array}{c}3051 \\
(1440-8480)\end{array}$ & $\begin{array}{c}2091 \\
(1433-5511)\end{array}$ & $\begin{array}{c}3957 \\
(1859-9881)\end{array}$ & ns \\
\hline REM & $\begin{array}{c}8525 \\
(2747-14537)\end{array}$ & $\begin{array}{c}4667 \\
(2366-7884)\end{array}$ & $\begin{array}{c}5037 \\
(2696-7884)\end{array}$ & $\begin{array}{c}4840 \\
(2887-11992)\end{array}$ & 0.048 \\
\hline \multicolumn{6}{|c|}{ LF/HF } \\
\hline Wake & $\begin{array}{c}1.01 \\
(0.76-1.72)\end{array}$ & $\begin{array}{c}1.16 \\
(0.86-1.82)\end{array}$ & $\begin{array}{c}1.57 \\
(1.22-2.12)\end{array}$ & $\begin{array}{c}1.35 \\
(0.87-1.76)\end{array}$ & ns \\
\hline NREM1\&2 & $\begin{array}{c}0.58 \\
(0.45-0.85)\end{array}$ & $\begin{array}{c}0.73 \\
(0.43-1.18)\end{array}$ & $\begin{array}{c}0.74 \\
(0.59-0.96)\end{array}$ & $\begin{array}{c}0.91 \\
(0.41-1.22)\end{array}$ & ns \\
\hline SWS & $\begin{array}{c}0.38 * \\
(0.26-0.55)\end{array}$ & $\begin{array}{c}0.39 * \\
(0.23-0.57)\end{array}$ & $\begin{array}{c}0.37 \\
(0.20-0.59)\end{array}$ & $\begin{array}{c}0.34 \\
(0.20-0.49)\end{array}$ & 0.03 \\
\hline REM & $\begin{array}{c}0.70 \\
(0.57-1.07)\end{array}$ & $\begin{array}{c}1.10 \\
(0.70-1.45)\end{array}$ & $\begin{array}{c}1.05 \\
(0.62-1.27)\end{array}$ & $\begin{array}{c}0.92 \\
(0.57-1.59)\end{array}$ & ns \\
\hline
\end{tabular}

Data are expressed as median (interquartile range). LF, low frequency; HF, high frequency; NREM, non rapid eye movement; REM, rapid eye movement; SWS, slow wave sleep.

$* \mathrm{P}<0.05$ vs MS OSA 
Table 4 Power spectral analysis of HRV comparing diagnostic groups within each sleep stage, during stable sleep

\begin{tabular}{|c|c|c|c|c|c|}
\hline & Control & PS & $\bar{M}$ & $\mathrm{M} / \mathrm{S}$ & $\mathrm{P}$ \\
\hline \multicolumn{6}{|c|}{$\mathrm{LF}\left(\mathrm{ms}^{2}\right)$} \\
\hline NREM1\&2 & $\begin{array}{c}1328 \\
(675-2356)\end{array}$ & $\begin{array}{c}1140 \\
(663-2780)\end{array}$ & $\begin{array}{c}1190 \\
(702-2245)\end{array}$ & $\begin{array}{c}2098 \\
(525-2359)\end{array}$ & ns \\
\hline SWS & $\begin{array}{c}855 \\
(325-1950)\end{array}$ & $\begin{array}{c}616 \\
(191-1403)\end{array}$ & $\begin{array}{c}452 \\
(238-1118)\end{array}$ & $\begin{array}{c}423 \\
(127-1204)\end{array}$ & ns \\
\hline REM & $\begin{array}{c}1735 \\
(562-2776)\end{array}$ & $\begin{array}{c}960 \\
(598-1912)\end{array}$ & $\begin{array}{c}733 \\
(572-1404)\end{array}$ & $\begin{array}{c}1027 \\
(618-2263)\end{array}$ & 0.043 \\
\hline \multicolumn{6}{|c|}{$\mathrm{HF}\left(\mathrm{ms}^{2}\right)$} \\
\hline NREM1\&2 & $\begin{array}{c}2112 \\
(727-5862)\end{array}$ & $\begin{array}{c}1646 \\
(813-3199)\end{array}$ & $\begin{array}{c}1541 \\
(911-6135)\end{array}$ & $\begin{array}{c}2217 \\
(971-3010)\end{array}$ & ns \\
\hline SWS & $\begin{array}{c}3536 \\
(996-5016)\end{array}$ & $\begin{array}{c}1279 \\
(598-4828)\end{array}$ & $\begin{array}{c}1482 \\
(383-2186)\end{array}$ & $\begin{array}{c}1638 \\
(468-2309)\end{array}$ & ns \\
\hline REM & $\begin{array}{c}1868 \\
(894-4363)\end{array}$ & $\begin{array}{c}850 \\
(562-3305)\end{array}$ & $\begin{array}{c}767 \\
(281-2867)\end{array}$ & $\begin{array}{c}1206 \\
(334-3877)\end{array}$ & 0.044 \\
\hline \multicolumn{6}{|c|}{ Total Power $\left(\mathrm{ms}^{2}\right)$} \\
\hline NREM1\&2 & $\begin{array}{c}4735 \\
(2803-11955)\end{array}$ & $\begin{array}{c}5044 \\
(2389-8515)\end{array}$ & $\begin{array}{c}4541 \\
(2506-15029)\end{array}$ & $\begin{array}{c}4464 \\
(3484-8465)\end{array}$ & ns \\
\hline SWS & $\begin{array}{c}5963 \\
(1943-11320)\end{array}$ & $\begin{array}{c}3306 \\
(1173-5883)\end{array}$ & $\begin{array}{c}2391 \\
(1299-5354)\end{array}$ & $\begin{array}{c}2938 \\
(704-3784)\end{array}$ & ns \\
\hline REM & $\begin{array}{c}5204 \\
(2506-11132)\end{array}$ & $\begin{array}{c}2605 \\
(1940-6615)\end{array}$ & $\begin{array}{c}3248 \\
(1968-7122)\end{array}$ & $\begin{array}{c}3026 \\
(2716-10435)\end{array}$ & 0.047 \\
\hline \multicolumn{6}{|c|}{$\mathrm{LF} / \mathrm{HF}$} \\
\hline NREM1\&2 & $\begin{array}{c}0.72 \\
(0.43-1.16)\end{array}$ & $\begin{array}{c}0.70 \\
(0.54-1.09)\end{array}$ & $\begin{array}{c}0.74 \\
(0.38-1.01)\end{array}$ & $\begin{array}{c}0.84 \\
(0.28-1.14)\end{array}$ & ns \\
\hline SWS & $\begin{array}{c}0.40 * \\
(0.24-0.59)\end{array}$ & $\begin{array}{c}0.45 * \\
(0.22-0.52)\end{array}$ & $\begin{array}{c}0.40 \\
(0.21-0.53)\end{array}$ & $\begin{array}{c}0.28 \\
(0.18-0.36)\end{array}$ & 0.02 \\
\hline REM & $\begin{array}{c}0.54 \\
(0.40-1.07)\end{array}$ & $\begin{array}{c}0.80 \\
(0.63-1.50)\end{array}$ & $\begin{array}{c}0.71 \\
(0.36-1.03)\end{array}$ & $\begin{array}{c}0.64 \\
(0.50-1.21)\end{array}$ & ns \\
\hline
\end{tabular}

Data are expressed as median (interquartile range). LF, low frequency; HF, high frequency; NREM, non rapid eye movement; REM, rapid eye movement; SWS, slow wave sleep.

$* \mathrm{P}<0.05$ vs MS OSA 
Table 5 Significant determinants of power spectral analysis of HRV

\begin{tabular}{lcccc}
\hline & Predictors & STD $\beta$ & Model R & P \\
\hline LF $\left(\mathrm{ms}^{2}\right)$ & & & & \\
Wake & Age & 0.34 & 0.12 & 0.002 \\
SWS & SDB Severity & -0.23 & 0.05 & 0.046 \\
REM & SDB Severity & -0.23 & 0.04 & 0.04 \\
HF $\left(\mathrm{ms}^{2}\right)$ & & & 0.05 & 0.04 \\
$\begin{array}{l}\text { Wake } \\
\text { Total Power }\left(\mathrm{ms}^{2}\right)\end{array}$ & BMI Z-score & -0.23 & & \\
Wake & Age & 0.30 & 0.09 & 0.008 \\
\hline
\end{tabular}

LF, low frequency; HF, high frequency; SDB, sleep disordered breathing; BMI, body mass index 
a. LF

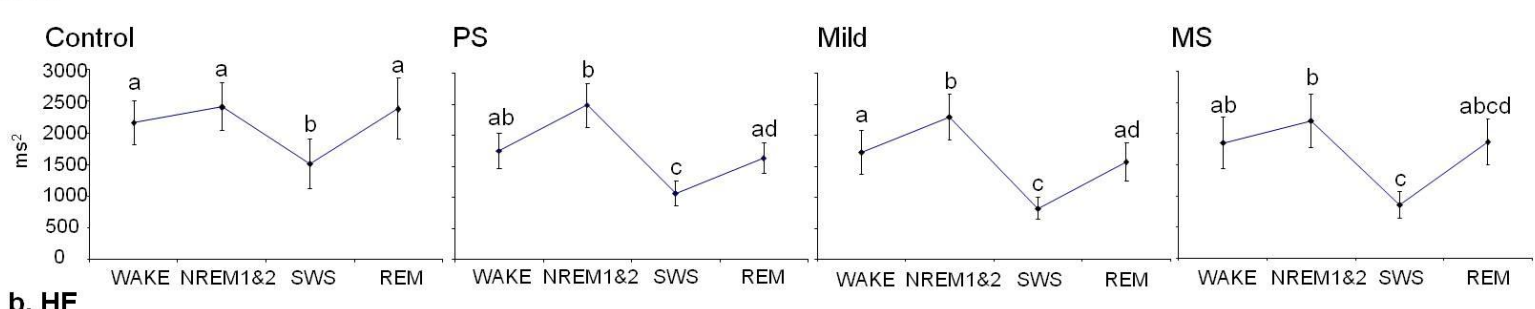

$\begin{array}{llll}\text { b. HF } & \text { Mild } & \text { MS }\end{array}$

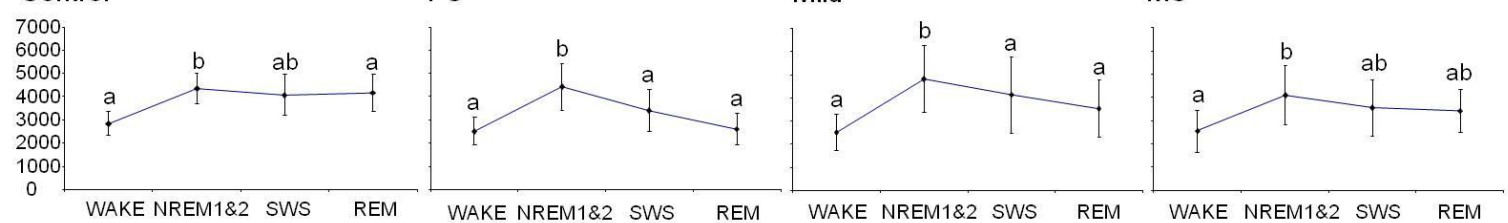

c. Total Power

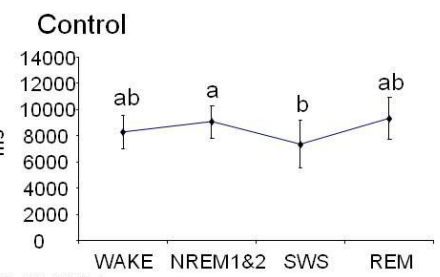

PS

Mild

MS

d. LF/HF

Control
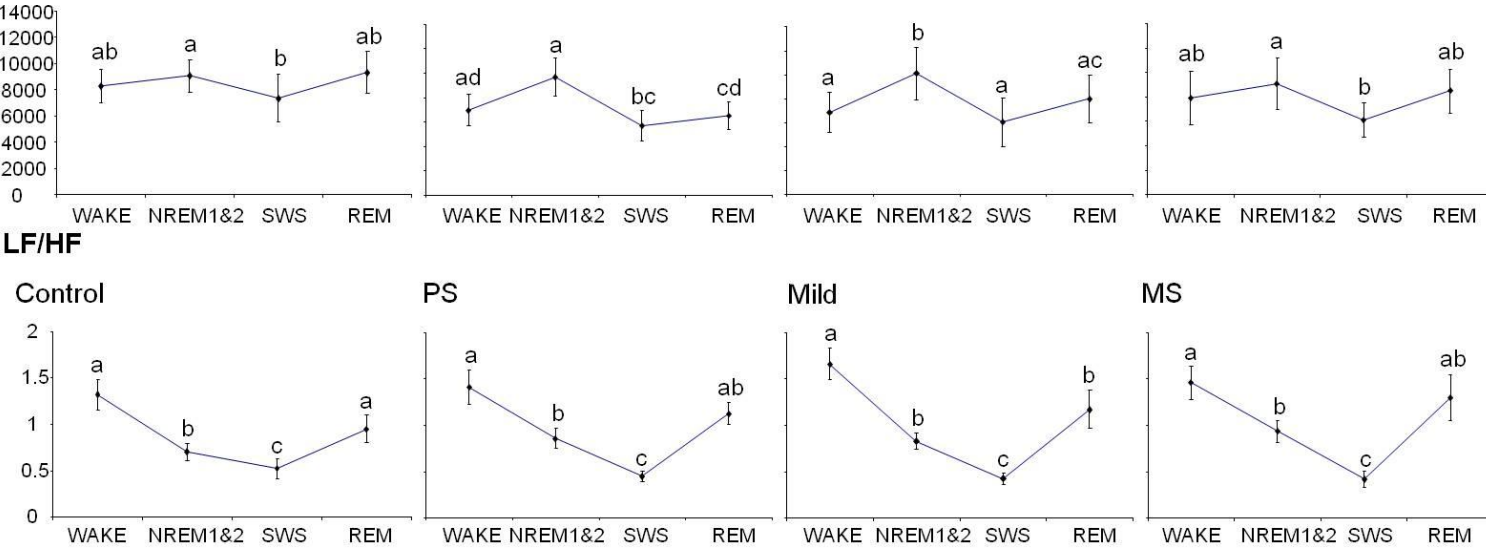

PS

Mild

MS

Mild
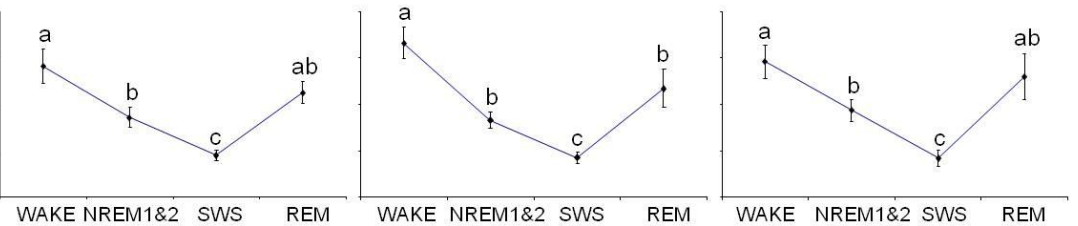